\section{$\underset{\substack{\text { hommes } \\ \text { \& migrations }}}{ }$}

\section{Hommes \& migrations}

Revue française de référence sur les dynamiques

migratoires

\section{$1329 \mid 2020$}

Migrations et création littéraire

\title{
Un fils
}

Fiction de Mehdi Barsaoui, (France, 2019)

\section{Mouloud Mimoun}

\section{(2) OpenEdition \\ 12 Journals}

\section{Édition électronique}

URL : https://journals.openedition.org/hommesmigrations/11262

DOI : 10.4000/hommesmigrations. 11262

ISSN : 2262-3353

\section{Éditeur}

Musée national de l'histoire de l'immigration

\section{Édition imprimée}

Date de publication : 1 avril 2020

Pagination : 191

ISBN : ISBN 978-2-919040-50-6

ISSN : 1142-852X

Référence électronique

Mouloud Mimoun, «Un fils », Hommes \& migrations [En ligne], 1329 | 2020, mis en ligne le 01 avril 2020, consulté le 02 janvier 2023. URL : http://journals.openedition.org/hommesmigrations/11262 ; DOI : https://doi.org/10.4000/hommesmigrations. 11262 


\section{Films}

\section{Unfils}

de Mehdi Barsaoui

(Fiction, France, 2019)

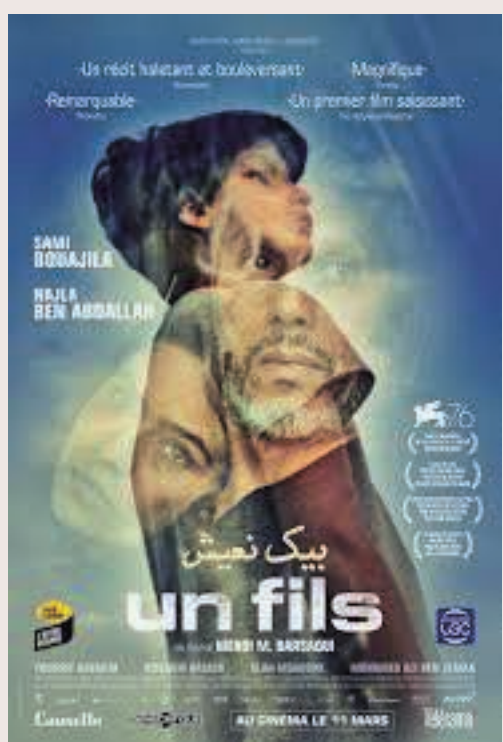

Inscrire la sphère intime - crise du couple - dans un contexte historique particulier - l'action se situant en 2011, sept mois après la chute du président Ben Ali -, telle est la gageure réussie par Mehdi Barsaoui pour son premier longmétrage, Un fils, couvert de récompenses internationales, la plus importante étant le prix du meilleur acteur pour Sami Bouajila dans la section Orizzonti de la Mostra de Venise 2019.

En préambule, quelques mots sur l'auteur-réalisateur: Mehdi Barsaoui a grandi à Tunis où il est né en 1984. Il est diplômé de l'Institut des arts multimédia de la capitale tunisienne et de la Dams de Bologne en Italie pour la réalisation de films. Il a trois courts-métrages à son actif, dont le dernier a remporté en 2016 le Muhr d'or du meilleur film à Dubaï.

Sami Bouajila, interprète principal d'Un fils, a déjà une longue carrière derrière lui. Originaire de Grenoble, il s'est révélé dans La Faute à Voltaire dirigée par Abdellatif Kechiche, avant de triompher au
Festival de Cannes en 2006 en obtenant le Prix du meilleur acteur, aux côtés de Jamel Debbouze, Samy Naceri, Roschdy Zem et Bernard Blancan, pour Indigènes de Rachid Bouchareb. De plus, il reçoit deux ans plus tard le César du meilleur acteur dans un second rôle pour Les Témoins d'André Téchiné.

Farès (Sami Bouajila) et Meriem (Najla Ben Abdallah, connue jusque-là surtout à la télévision) forment, avec leur fils de neuf ans, Aziz, une famille tunisienne plutôt moderne et issue d'un milieu privilégié. Au volant de leur Range Rover - une voiture qui coûte très cher en Tunisie -, ils se rendent dans le Sud. La première scène du film est significative du lien très fort qui unit le père et le fils, le plan s'attardant sur les mains entremêlées de Farès et Aziz sur le volant. Mais, soudain, le véhicule est pris pour cible par un groupe terroriste qui s'attaquait à des gendarmes et le jeune garçon est grièvement blessé à l'abdomen...

Dès lors, le drame va se nouer. Le chirurgien leur annonce que le jeune enfant doit subir une greffe du foie et qu'il ne peut la recevoir de son père dont l'analyse de sang révèle qu'il n'est pas son père biologique. Coup de massue sur la tête de Farès qui apprend ainsi son infortune: son épouse s'est rendue coupable d'adultère... un crime sévèrement puni en Tunisie. Bien évidemment, la relation de couple va se détériorer, d'autant qu'il faut retrouver l'amant, lequel est bien sûr susceptible d'être compatible avec l'enfant. Ne pouvant recevoir de greffon car trop loin sur la liste des demandeurs, Aziz reste la préoccupation première de Farès, quand un trafiquant lui propose une transaction sous forme d'achat auprès d'un autre enfant issu d'un milieu défavorisé...

Mais pourquoi avoir situé l'action du film en 2011? À cela Mehdi Barsaoui répond: «En Tunisie, l'année 2011 a été une année charnière sur les plans politique et social. Le récit se déroule en août et en septembre, sept mois après la révolution. Il me paraissait important que l'action se déroule à cette période précise car cela me permettait d'ajouter un contexte social et historique à l'histoire. Au départ, je n'avais pas la prétention de vouloir parler de la révolution: je n'en avais ni les connaissances nécessaires, ni les moyens. Je ne suis ni historien ni politologue. Ce qui m'intéressait, c'étaient les répercussions que la vie politique pouvait avoir sur une famille d'allure classique. »

Et, de fait, la réussite du film repose en grande partie sur la sphère personnelle et intime du couple, à aucun moment parasitée par les considérations politiques et historiques, au point que "l'intrigue se concentre toujours sur le drame qui saisit la famille». Le réalisateur lui-même est issu d'un couple divorcé, ayant vécu avec sa mère et deux demi-frères.

Aussi, on comprend mieux la problématique d'Un fils qui, au fond, s'interroge avec pertinence et talent sur la question de la filiation et les liens du sang. Mouloud Mimoun 